\title{
Análisis sísmico de gradas con tres modelos mediante los métodos: espectral y del espectro de capacidad, que sirven de acceso a una estructura con aisladores sísmicos Seismic analysis of stairs with three models using the spectral and the capacity spectrum methods, give access to a building with seismic isolators
}

\author{
R. Aguiar ${ }^{1 *}$, D. Mora **, D. Muñoz ***, S. Serrano ***, D. Vera ***, M. Rodríguez *, D. Páez ***
}

* Universidad de Fuerzas Armadas ESPE, Quito. ECUADOR

** Escuela Politécnica Nacional, Quito. ECUADOR

*** Universidad Laica Eloy Alfaro de Manabí, Manta. ECUADOR

Fecha de Recepción: 26/01/2017

Fecha de Aceptación: 22/09/2017

PAG 113-130

\begin{abstract}
At the Universidad de las Fuerzas Armadas - ESPE, in Ecuador, different structural blocks with and without seismic isolators of triple friction pendulum are being built. In one of them, the access stairs to the floors is located in a Structural Block with no seismic isolators; therefore, it has special construction details to allow a free displacement of the Isolators' Building without impacting the Stairs' Building at all. This paper addresses these details. On the other hand, three models (each with different degrees of freedom) for seismic analyses of a longitudinal frame and a transversal frame are shown. The results were obtained and compared using the Spectral Method and the Capacity Spectrum Method. Moreover, these results highlight the importance of appropriately selecting the numerical calculation model. Later on, the seismic analysis of the Structural Block of the Access Stairs is shown, using a three-phase constitutive model.
\end{abstract}

Keywords: Spectral Method; Capacity Spectrum Method; Seismic Isolators; Access Stairs.

Resumen

En la Universidad de las Fuerzas Armadas ESPE de Ecuador, se están construyendo algunos Bloques Estructurales con aisladores sísmicos de triple péndulo de fricción. En uno de ellos, las gradas de acceso a los diferentes pisos se encuentran en un Bloque Estructural sin aisladores sísmicos, por lo que tiene detalles especiales en su construcción para permitir el libre desplazamiento de los aisladores sin posibilidad de impacto con el Bloque de Gradas. En este artículo se indican esos detalles. Por otra parte, se presentan tres modelos con diferentes grados de libertad para el análisis sísmico de un pórtico en sentido longitudinal y de un pórtico en sentido transversal de la grada; se compara sus respuestas empleando el Método Espectral y el Método del Espectro de Capacidad. Destacando con ello la importancia de seleccionar en forma apropiada el modelo numérico de cálculo. Posteriormente se presenta el análisis sísmico del Bloque Estructural al que dan acceso las gradas, utilizando como constitutiva un modelo de tres fases.

Palabras clave: Método espectral, método del espectro de capacidad, aisladores sísmicos, gradas de acceso

\section{Introduction}

The Universidad de las Fuerzas Armadas - ESPE, located in the Valley of Los Chillos, is building eight structural blocks that will house the Research and Postgraduate Centers. Structural Blocks 1, 2, 3, 6, 7 and 8 have seismic isolators of triple friction pendulum (TFP) and the 4" and 5" blocks have Shear Link energy dissipators. Figure 1 shows an overview of the mentioned Structural Blocks, which total a construction area of approximately 23,500 square meters.

\footnotetext{
1 Corresponding author:

Head Professor of the Department of Earth Sciences and Construction E-mail: rraguiar@espe.edu.ec
}

The emergency stairs was built with steel square tubular columns of 250/250/20 mm and "I" beams of 400/200/15/12 mm, in Structural Blocks without seismic isolators, which also contain the elevator structure. The circles in Figure 1 show the emergency stairs analyzed in the present paper, which gives access to the 1" and 7" Structural Block.

Figure 2a) shows the structural block without isolators, containing the stairs and the elevator. The seismic analysis of the J-Frame (longitudinal) and the 7 ' Frame (transverse) will be described further on.

On the other hand, Figure $2 b$ ) shows the development of the stairs, where to go up from one floor to another there are three inclined segments and two landings between axes J - $J^{\prime \prime}$. The elevator is located between axes $J^{\prime}-J^{\prime \prime \prime}$ and axes $7 \mathrm{a}$ - $7 b$. There is a room on the back of the elevator (axes $J-J$ ), on the right side (axes $7 b-6 a$ ).

The entrance to one of the Structural Blocks with isolators, for example to Block 7, is from axis I. The problem to be solved is how to build the joint between the 7" Structural Block with TFP isolators, which will show a 
considerable lateral displacement $(60 \mathrm{~cm} G A P)$, and the Stairs Block indicated in Figure 2.

The solution given to prevent the impact of these two structures during an earthquake is shown in Figure 3a) for the stairs and in Figure 3b) for the elevator. The stairs shows that the last step is the cantilever beam of the Structural Block 7. The steel steps reach $7 \mathrm{~cm}$, except those of the slab of Block 7 , so that they can move independently without impact. In the upper part of a floor, the first step is also located at $7 \mathrm{~cm}$ of the slab; see Figure 4. It is important to note that the step moves independently from the Isolated Block, so that they do not impact with each other; therefore, the deck has two slabs at different heights.

Figure $3 b)$ shows the access from the elevator to the Block with isolators. Here, there is a cantilever beam at a lower level than the isolated structure; on top of the beam there is a flexible foam filling, so that people coming out of the elevator can walk at a single level. During an earthquake, the filling is expected to break, so that the isolated Block can have a complete displacement. Evidently, the flexible foam will be replaced after the earthquake, if necessary.

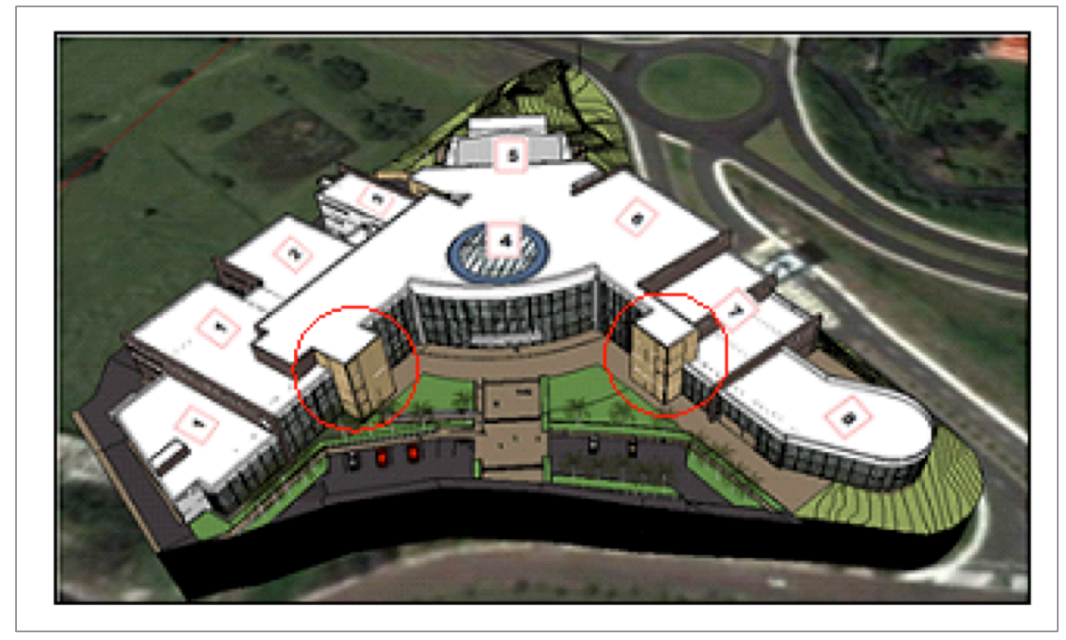

Figure 1. Overview of the Structural Blocks, where the UFA-ESPE Research and Postgraduate Centers will operate

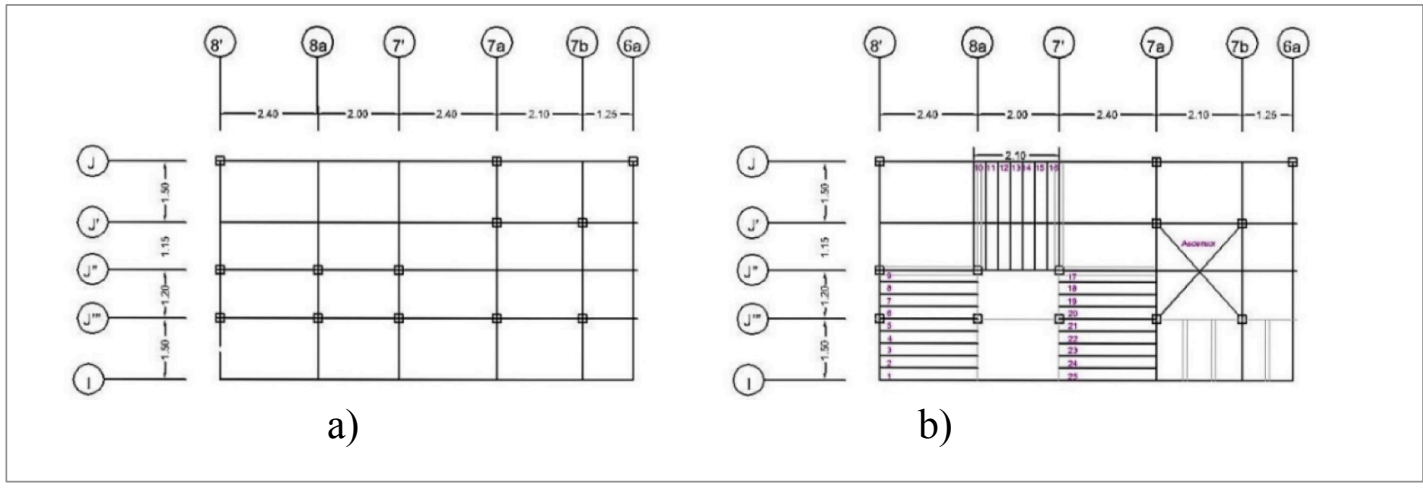

Figure 2. Plan view of the Structural Block without isolators: a) Implementation of Columns; b) Stairs Development 


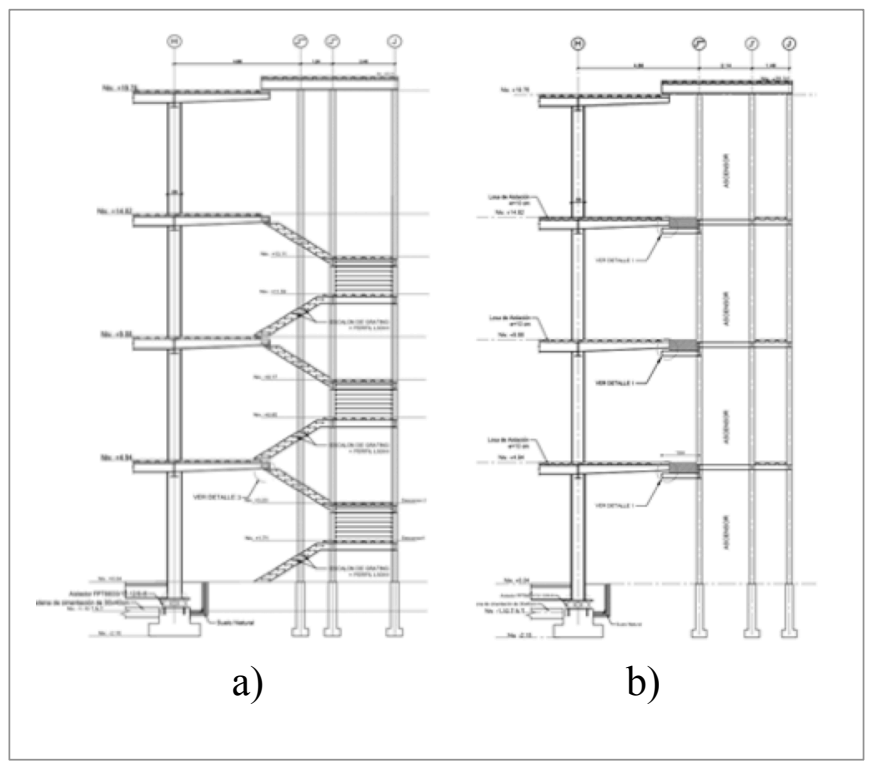

Figure 3. Detail of the entrance to Structural Block 7 with seismic isolators: a) Access by stairs; b) Access by elevator. Source: Aguiar and Pazmiño (2016)

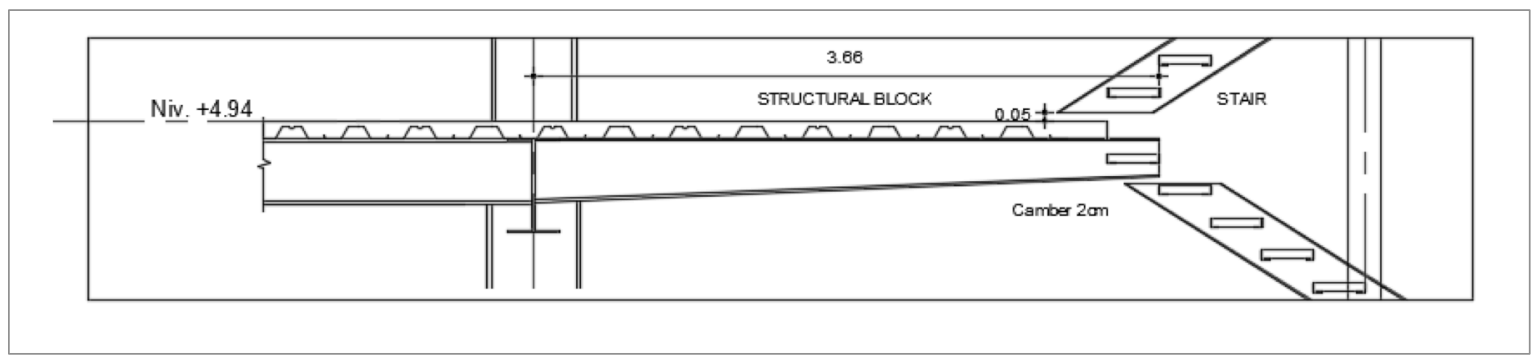

Figure 4. Construction detail of the steps to or from the Structural Block with isolators

\section{Numerical models for analyzing the longitudinal frame}

Apparently, stairs are a very simple structure, so that sometimes the seismic analysis is even ignored or it is made with extremely elemental models, which do not report adequate results. Therefore, a seismic analysis of the stairs from the Access Block to the 7" Structural Block was defined.

A 2D seismic analysis is applied to the longitudinal JFrame and the transverse $7^{\prime}$ frame. This section describes the J-Frame; therefore, Figure 5a) indicates the frame geometry and Figures 6a) and 7a) present two calculation approaches, which are actually used to simplify the analysis, so as not to work with inclined elements, but as we will see, it conduces to different results.
Figure 5b) shows the degrees of freedom for the model associated to Figure 5a), which has 10 lateral coordinates and 55 degrees of freedom in total. Therefore, a direct assembly of 55 by 55 will calculate the stiffness matrix, which is condensed to a matrix of 10 by 10 for a seismic analysis (Model M10).

Regarding the simplified model analysis of Figure 6a), Figure 6b) shows 7 lateral coordinates and 40 degrees of freedom; thus, the lateral stiffness matrix associated to the lateral coordinates is 7 by 7 (Model M7).

Finally, the third model presented in Figure 7a) has 4 lateral coordinates and 31 degrees of freedom; see Figure 7b), (Model M4). 


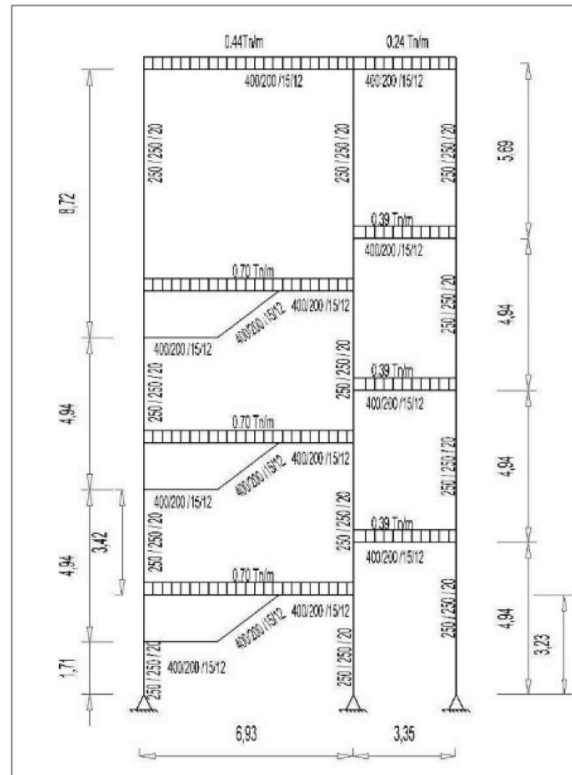

a)

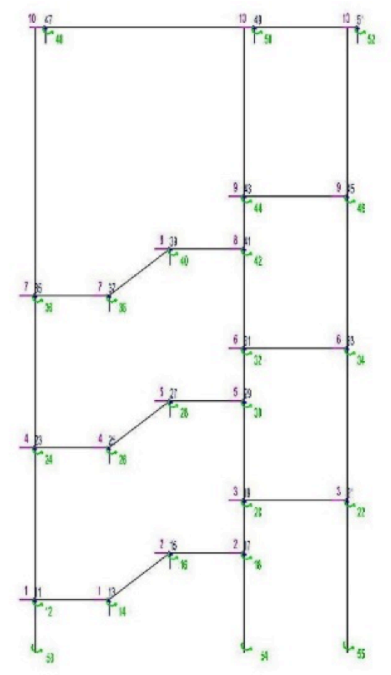

b)

Figure 5. a) Geometry and loads of J-Frame, b) Model with 10 primary coordinates

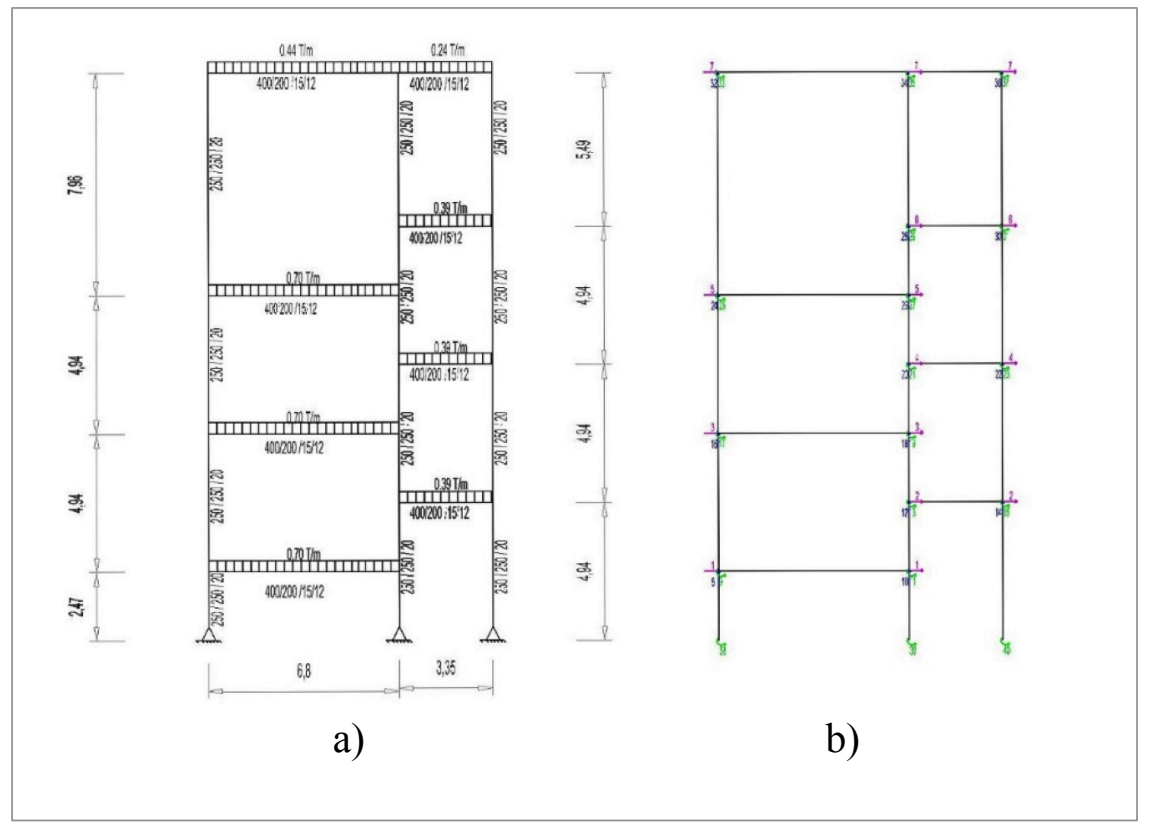

Figure 6. a) Geometry and loads of J-Frame, b) Model with 7 primary coordinates 


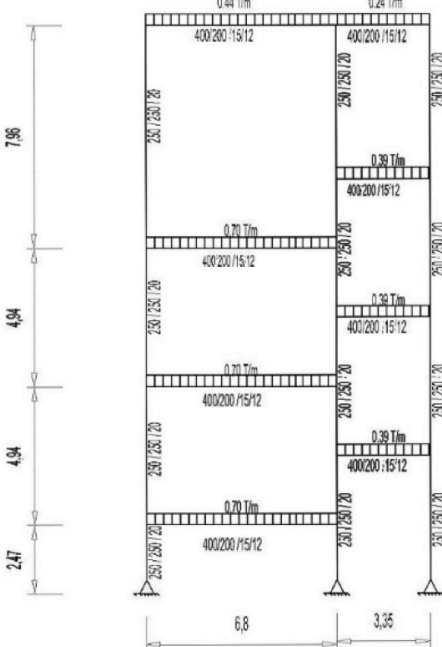

a)

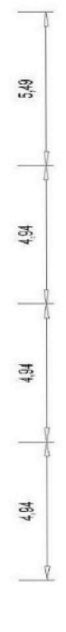

亚

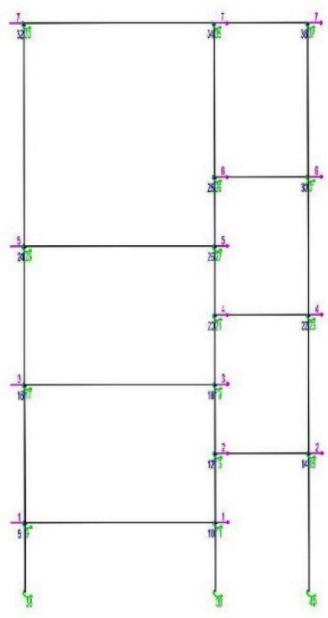

b)

Figura 7. a) Geometry and loads of J-Frame, b) Model with 4 primary coordinates

Annex A includes the theoretical frame of the Spectral Method. In both cases, the seismic analysis is the one recommended by the Ecuadorian Construction Standard NEC-15 for a seismic region whose PGA is $0.4 \mathrm{~g}$ for a type-C ground.

\section{Results with the Spectral Method}

Table 1 shows the analysis model; the fundamental period of vibration $T$, the maximum lateral displacement $q$, the floor drift $y$, and the base shear $V$ in the J-Frame, using the
Spectral Method, with a seismic force reduction factor $R=4$. It can be seen that the model with 10 degrees of freedom M10 reports the smallest period, and the same occurs with the lateral displacement. The lowest floor drift occurs with model M7 and the lowest shear, with model M4.

Figure 8a) shows the lateral displacements with each model, and Figure 8b) shows the floor drifts. The Model M4 is the most simple, but it should not be used because it reports very high values and it also differs from the geometry of the stairs. It is feasible to work with Model M7, but it is best to use $\mathrm{M} 10$.

Table 1. Results of the seismic analysis of the J-Frame. Spectral Method

\begin{tabular}{|c|c|c|c|c|}
\hline Model & $T$ & $q$ & $\gamma$ & $V_{0}$ \\
& $(\mathrm{~s})$. & $(\mathrm{cm})$ & $(\%)$ & 5.36 \\
\hline M10 & 0.483 & 9.57 & 1.5 & 5.64 \\
\hline M7 & 0.542 & 12.32 & 1.3 & 4.46 \\
\hline
\end{tabular}




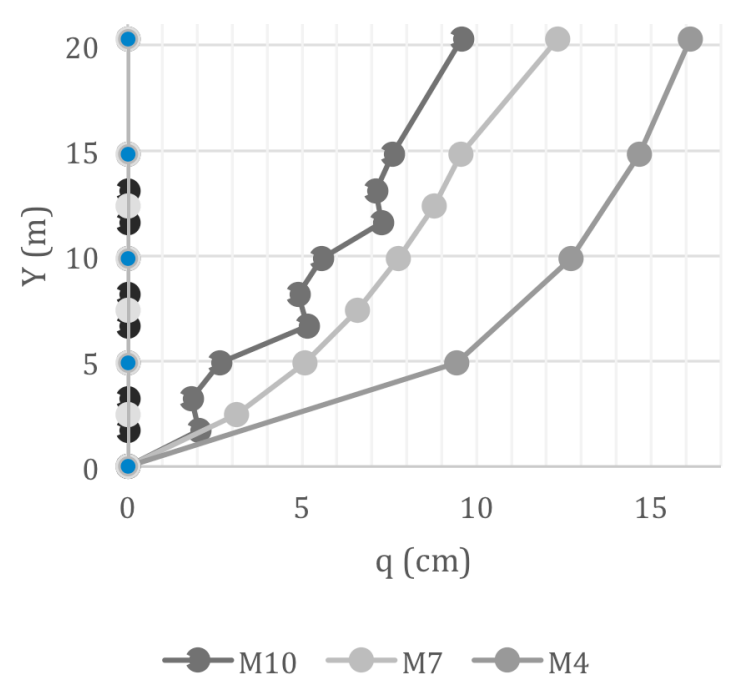

a)

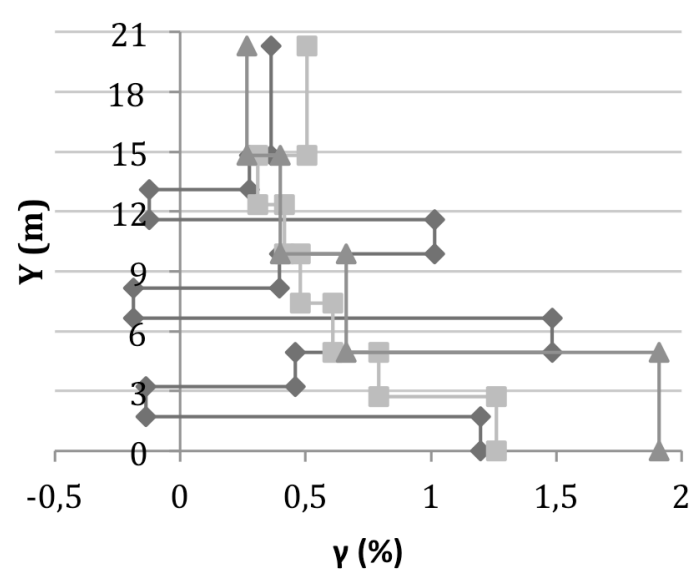

$\multimap$ M $10-$ M $7 \multimap$ M 4

Figure 8. a) Lateral Displacements b) Floor Drifts, of J-Frame

\section{Results with the Capacity Spectrum Method}

The graphs at the left of Figure 9a show the seismicresistant capacity curve that relates the base shear and the displacement on the top, through a monotonic pushover. Then, the performance point was found; therefore, the center part of Figure 9 shows the structure's capacity spectrum (green line), the design spectrum of NEC-15 (red line) and the point that allows finding the design point (blue line) when applying the Capacity Spectrum Method described in Annex $B$.

Finally, the graphs at the right of Figure 9 correspond to the damage level that the structure will suffer during the earthquake. The green color means that the section exceeded the plastic moment $M$ and entered the nonlinear range. Other structures may also present a red color, which means that a plastic hinge was formed in the section, but it was not the case in the studied structure.

Figure 9a) corresponds to the analysis with the model of 10 degrees of freedom M10, where the structure works elastically, because no colors are observed on the graph to the right.
Figure 9b) corresponds to the model M7, analyzed with 7 degrees of freedom, where the structure does not suffer any damage either. Lastly, Figure 9c) shows the performance with the model M4. In this case, there are two sections that have exceeded the plastic moment, which correspond to the central column in the upper part and the beam located on the right of the first floor. This is because the model M4 reports big displacements.

Table 2 presents the results obtained with the Capacity Spectrum Method in the J-Frame, and indicates the analysis model, the displacement corresponding to the design point $(q)$ and the associated acceleration $(A)$, the displacement on the top of the structure $(q)$, the floor drift $y$ and the base shear $(V)$. The resulting displacements and floor drifts are similar to those found with the Spectral Method, indicated in Table 1. The base shear is different, because the shear in Table 1 has been divided for $R=4$, in the Spectral Method, and now there is an elastic base shear. 
Table 2. Results of the seismic analysis of J-Frame. Capacity Spectrum Method

\begin{tabular}{|c|c|c|c|c|c|}
\hline Model & $\begin{array}{c}q(m) \\
1 \text { gdl }\end{array}$ & $A\left(\frac{m}{s^{2}}\right)$ & $q_{T}(m)$ & $\gamma(\%)$ & $V_{0}(T)$ \\
\hline M10 & 0.075 & 11.033 & 0.105 & 1.739 & 23.93 \\
\hline M7 & 0.103 & 11.565 & 0.134 & 1.762 & 24.06 \\
\hline M4 & 0.153 & 9.259 & 0.179 & 2.271 & 20.12 \\
\hline
\end{tabular}

a)
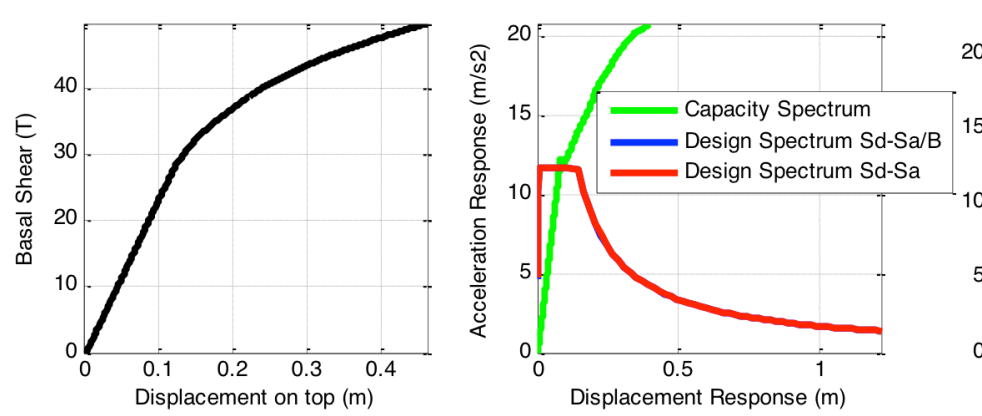

Structure and hinge scheme

b)
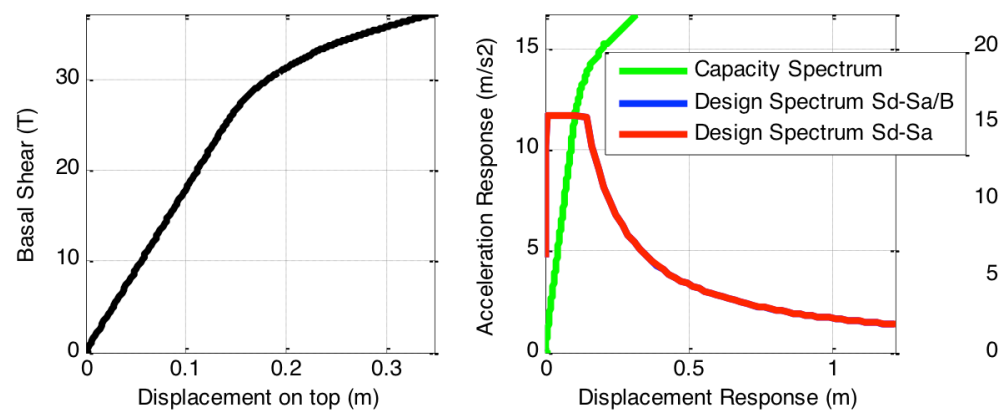

Structure and hinge scheme

c)
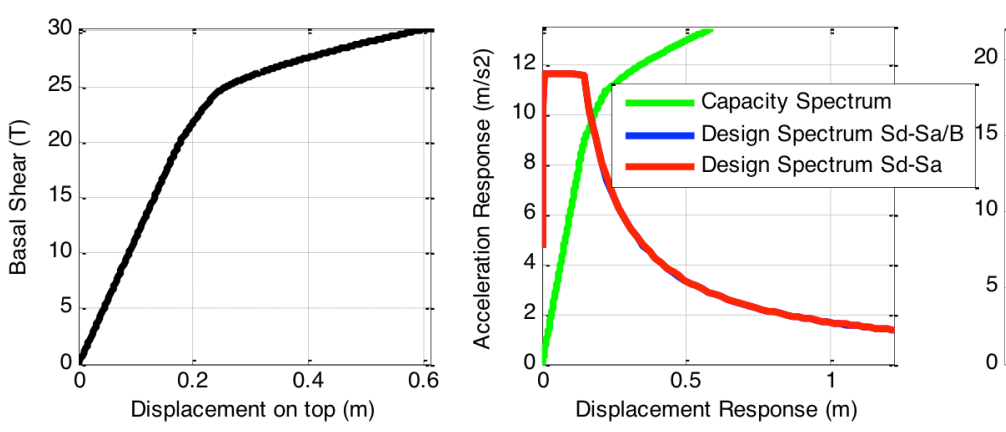

Structure and hinge scheme

Figure 9. Seismic-resistant capacity, Capacity Spectrum Method, and zones with damage on J-Frame, a) Model M10, b) Model M7, c) Model M4 


\section{Numerical models for analyzing the}

transverse frame

Figures 10 to 12 present the geometry, loads, sections of the elements for the $7^{\prime}$ Frame, and the analysis models M10, M7 and M4, with a seismic analysis considering 10, 7 and 4 degrees of freedom, respectively, in the presence of a design basis earthquake (DBE).

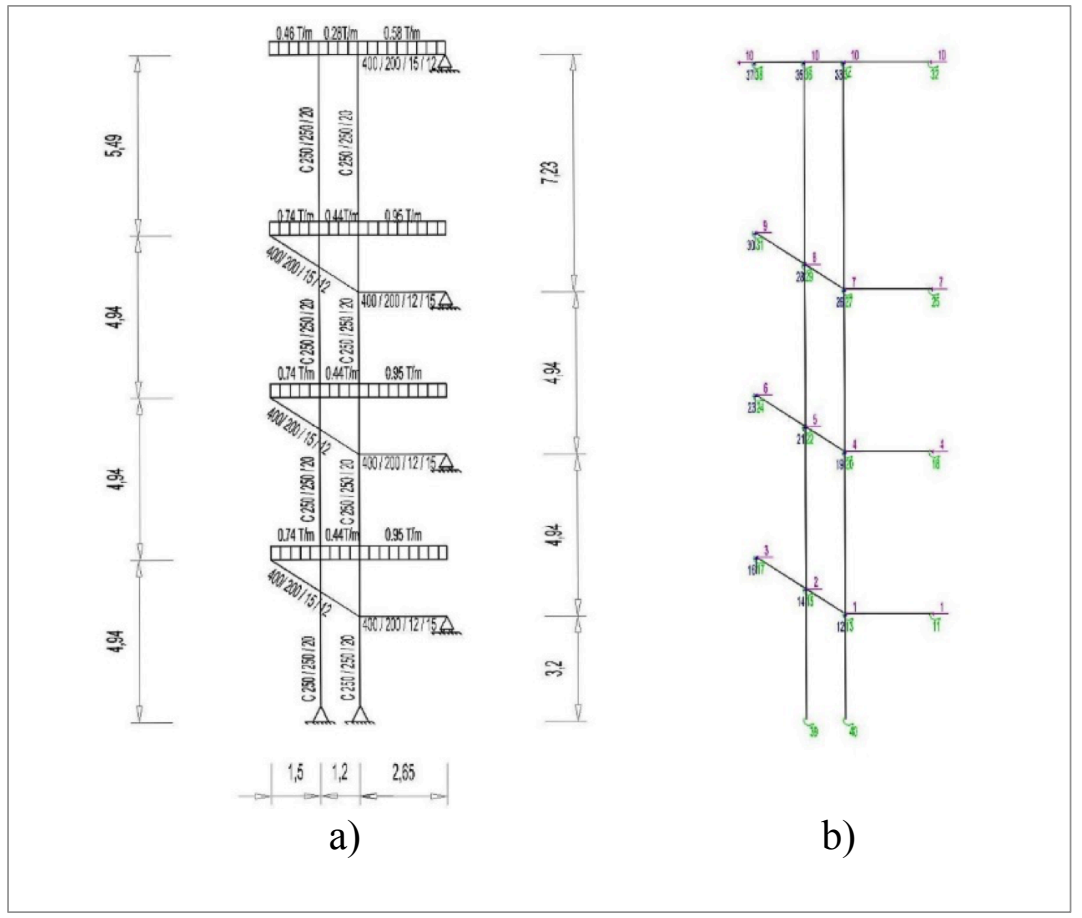

Figure 10. 7' Frame a) Geometry and loads, b) Model with 10 primary coordinates

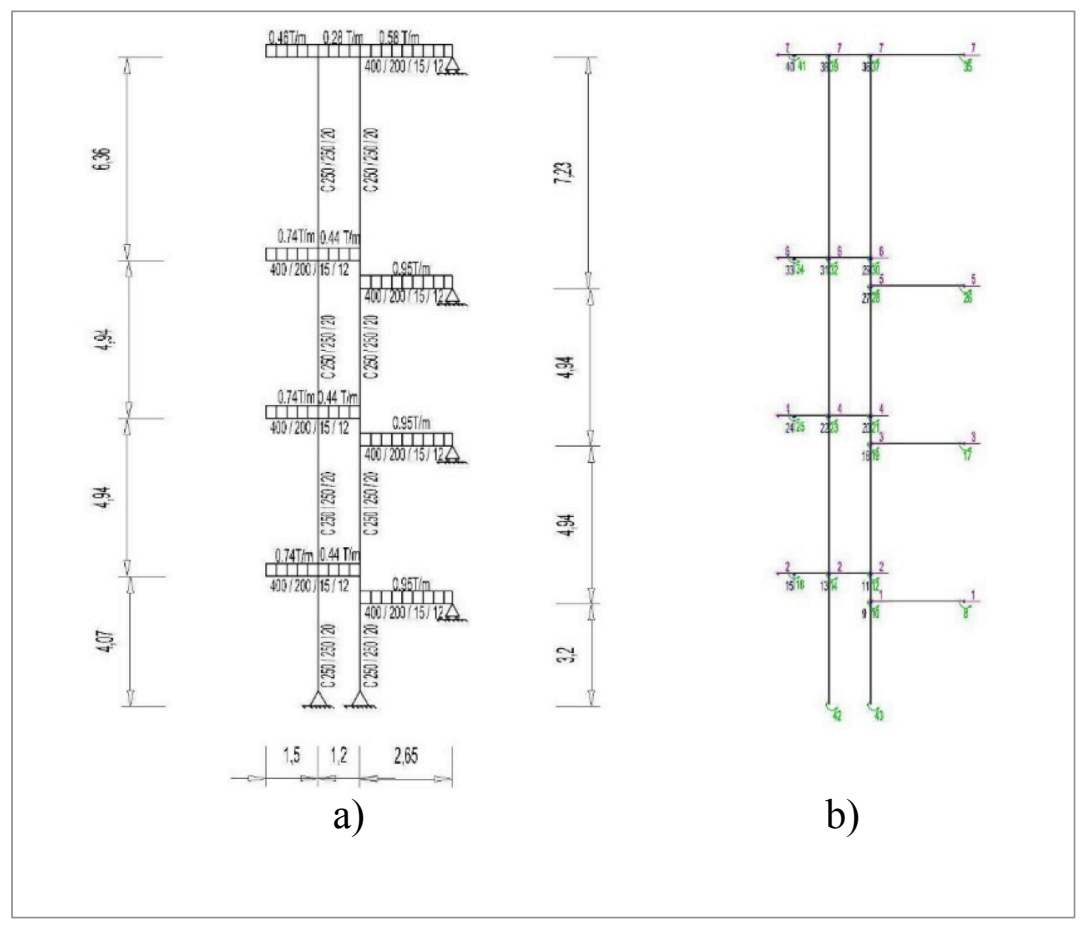

Figure 11. 7' Frame a) Geometry and loads, b) Model with 7 primary coordinates 


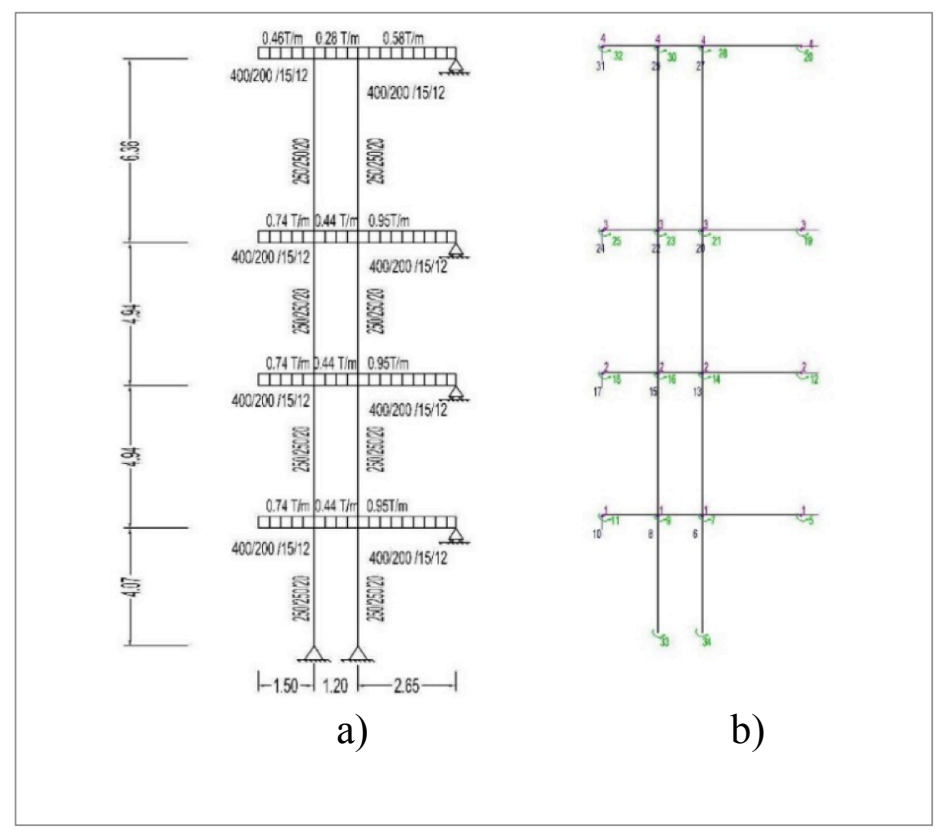

Figura 12. 7' Frame a) Geometry and loads, b) Model with 4 primary coordinates

Table 3 indicates the results of the seismic analysis of the $7^{\prime}$ Frame. Once again, the results of model M4 are different compared with the other models and the best is to work with model M10.
Figure 13 shows the displacements and floor drifts obtained with models M10, M7 and M4 for the 7' Frame

Table 3. Results of the seismic analysis of the 7' Frame

\begin{tabular}{|c|c|c|c|c|}
\hline Model & $\begin{array}{c}T \\
(\mathrm{~s})\end{array}$ & $\begin{array}{c}q \\
(\mathrm{~cm})\end{array}$ & $\begin{array}{c}\gamma \\
(\%)\end{array}$ & $\begin{array}{c}V_{0} \\
(T)\end{array}$ \\
\hline M10 & 0.597 & 14.00 & 1.30 & 3.66 \\
\hline M7 & 0.579 & 13.46 & 1.48 & 3.96 \\
\hline M4 & 0.652 & 14.51 & 1.48 & 3.53 \\
\hline
\end{tabular}

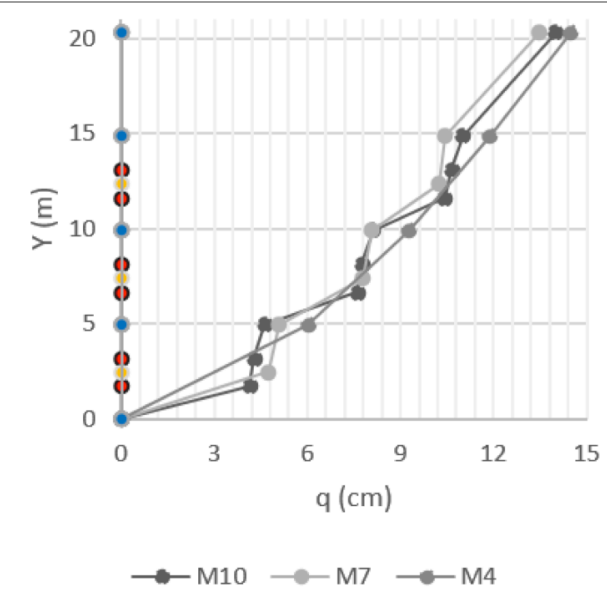

a)

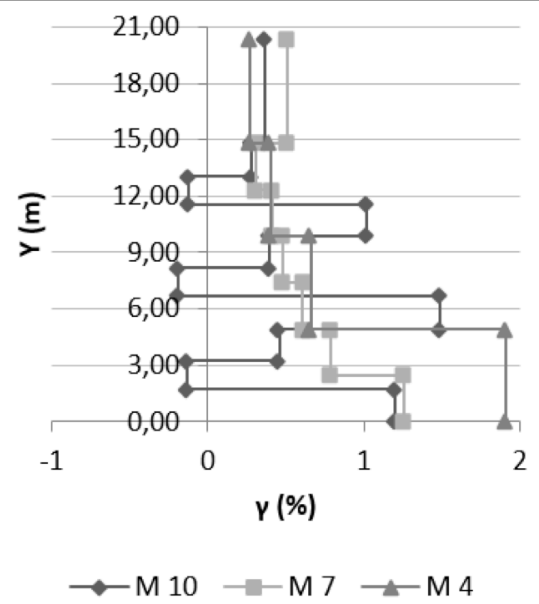

b)

Figure 13. a) Lateral displacements and b) Floor drifts of the $7^{\prime}$ Frame 


\section{Results with the capacity spectrum method}

The results obtained with the Capacity Spectrum Method in the 7' Frame, with models M10, M7 and M4, are indicated in Figure 14 and their maximum values are indicated in Table 4. Likewise, the model M4 is not reliable. It should be noted that in model M10, the final knot from a column of the first floor enters the nonlinear range (green color).

a)
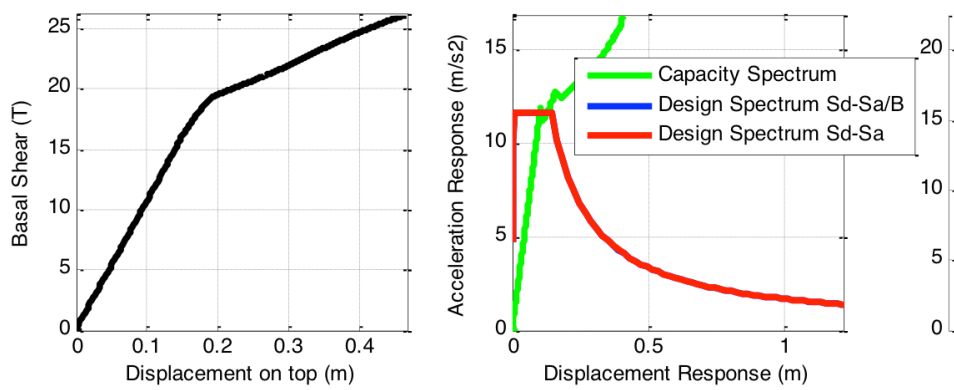

Structure and hinge scheme

b)
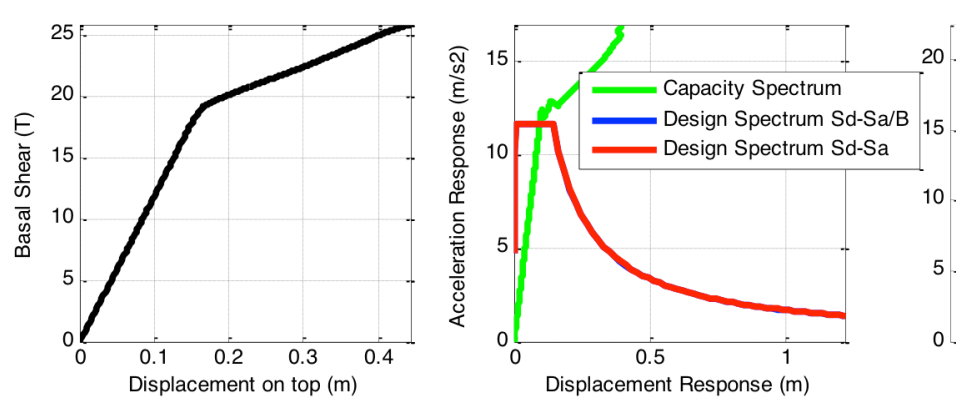

Structure and hinge scheme

c)
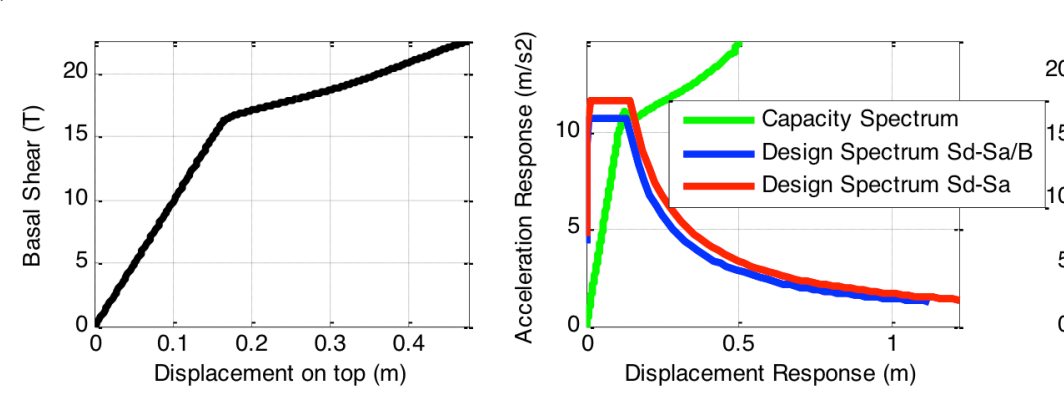

Structure and hinge scheme

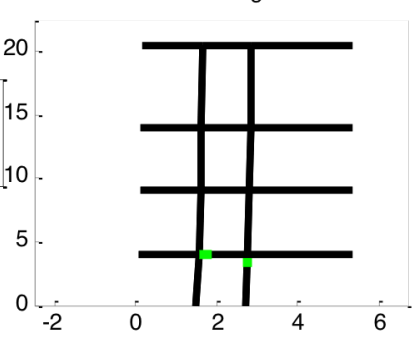

Figure 14. Seismic-resistant capacity, Capacity Spectrum Method and damaged zones on the 7' Frame, a) Model M10,

b) Model M7, c) Model M4 
Table 4. Results of the seismic analysis of the 7' Frame. Capacity Spectrum Method

\begin{tabular}{|c|c|c|c|c|c|}
\hline Model & $\begin{array}{c}q(m) \\
\text { 1gdl }\end{array}$ & $A\left(\frac{m}{s^{2}}\right)$ & $q_{T}(m)$ & $\gamma(\%)$ & $V_{0}(T)$ \\
\hline M10 & 0.114 & 11.238 & 0.153 & 1.507 & 16.41 \\
\hline M7 & 0.092 & 11.18 & 0.129 & 1.417 & 15.34 \\
\hline M4 & 0.127 & 11.089 & 0.162 & 1.709 & 15.99 \\
\hline
\end{tabular}

Again, the results reported by the Capacity Spectrum Method are quite similar to those reported by the Spectral Method at the level of lateral displacements and floor drifts. In order to compare the shears, the values reported by the Spectral Method should be multiplied by $R=4$.

\section{Seismic analysis of structural blocks with Isolators}

The analyzed Stairs Block gives access to the $6^{*}$ and 7 Structural Block on the cantilever side of $3.51 \mathrm{~m}$, located on the $W$-axis in Figure 15. The entrance is located between axes 39 and 41. Bays 32-33 and 33-36 have a basement; therefore, initially, the idea was to build this sector independently from the other bays. These two bays formed the $6^{\text {th }}$ Building and the rest formed the $7^{\text {th }}$ Building

If the structure has no isolators, Blocks 6 and 7 should be built with a construction joint, since the 7" Block has anirregular elevation. However, if they have seismic isolators, in this case the triple friction pendulum (TFP), the best is to build without joints, because, on the one hand, the column axis is eliminated with its respective isolators that should be put in the joint. On the other hand, it avoids using special pipes to pass plumbing or electrical facilities from one block to another. Finally, if a construction joint is used, there is a problem to be solved regarding the approximately one-meter gap on the façade, which is caused when isolators are installed and two independent blocks are built.

Therefore, the best is a single Structural Block, referred to as 6-7, where TFP isolators are placed on top of reinforcedconcrete columns of $80 / 80 \mathrm{~cm}$, on the basement side and above the pedestals of $120 / 120 \mathrm{~cm}$, coming out from the plinths in axes 39, 41 and 43. The isolators have a length of approximately one meter; therefore, a basket of $120 / 120 \mathrm{~cm}$ was built on top of the $80 / 80 \mathrm{~cm}$ columns, as shown on the left side of Figure 16, and the isolators for the three mentioned axes are shown on the right side.

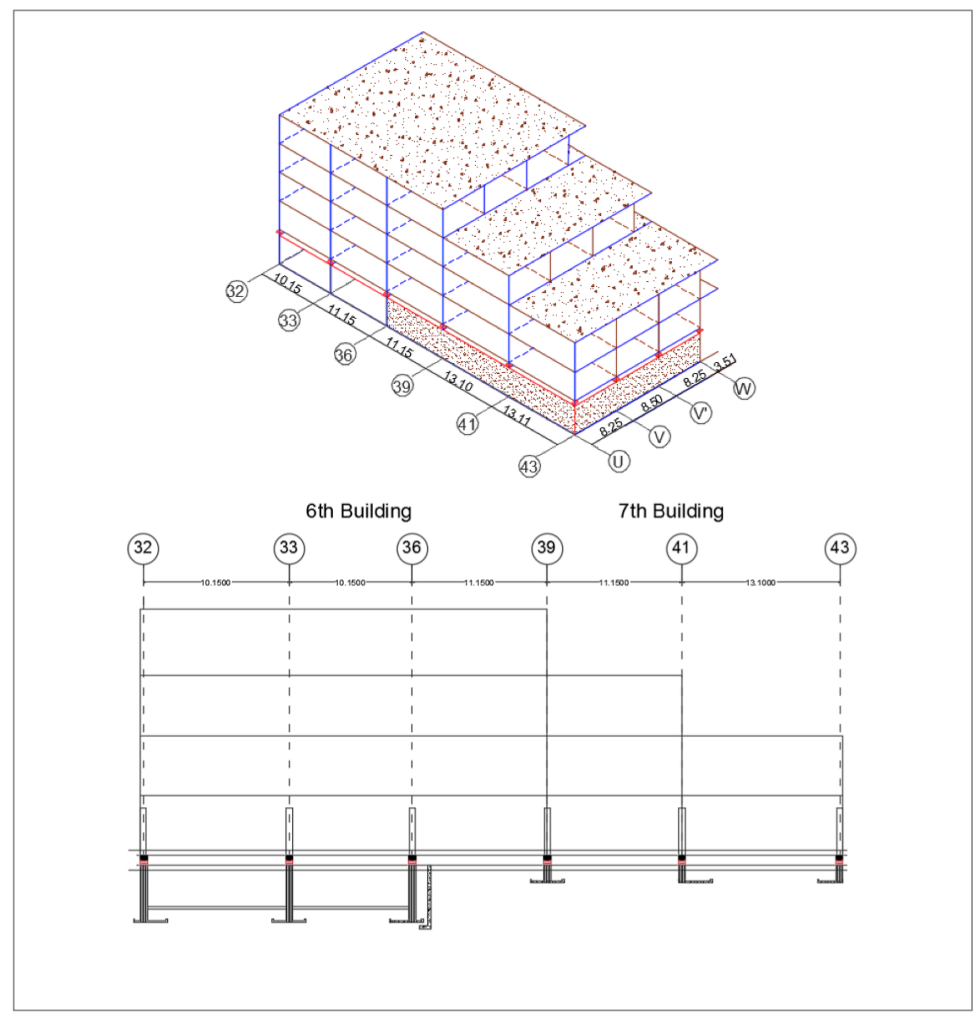

Figure 15. Structural Block 6 and 7 with TFP isolators, where the stairs are connected to bays 39-41 on the cantilever side of 3.51 m. Source: Aguiar and Pazmiño (2016) 


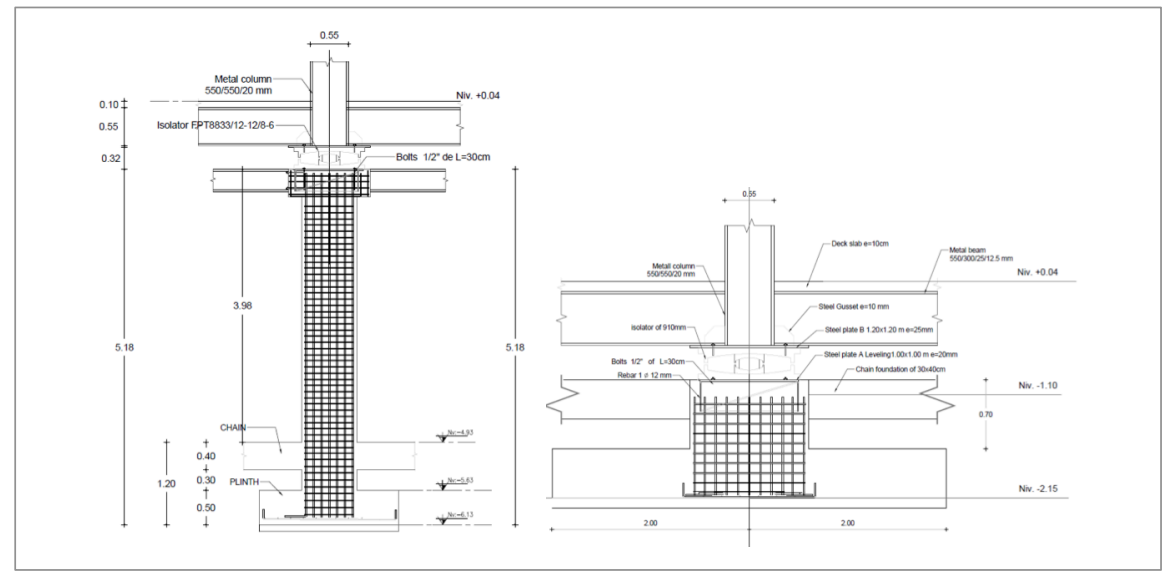

Figure 16. TFP isolator on top of concrete columns and on top of the pedestal in Block 6-7. Source: Aguiar and Pazmiño (2016)

Annex $C$ addresses the theoretical frame of the threephase model proposed by McVitty and Constantinou (2015), concerning the force-displacement constitutive curves of isolators, which was used in the seismic analysis with the Spectral Method. Figure 17 indicates the displacements in the $X$-direction and the $Y$-direction for design basis earthquakes $D B E$ (obtained with NEC-15, for a return period of 475 years) and maximum considered earthquakes MCE (obtained by multiplying the DBE by 1.4 and it has a recurrence interval of 1,000 years, Constantinou et al., 2016).

Displacements in the Y-direction are towards axes 8', $7^{\prime}, 7 \mathrm{a}$ and $6 \mathrm{a}$ of the access stairs. It is observed that, in the event of a MCE, maximum lateral displacements of approximately $47 \mathrm{~cm}$ are expected in the isolated block.

Figure 17 also shows lateral displacements considering the non-isolated structure, which seems to have almost the same displacement or a bit less, but there is a great difference: in the structure with isolators, the isolator shows the greatest displacement (horizontal line) and the structure above shows a very small displacement in relation to the isolators' displacement.

Thus, the structure without isolators is damaged, because it suffers important displacements, while the structure with isolators has relatively small displacements. 


\section{Displacement for DBE earthquake in $X$ and $Y$ direction}

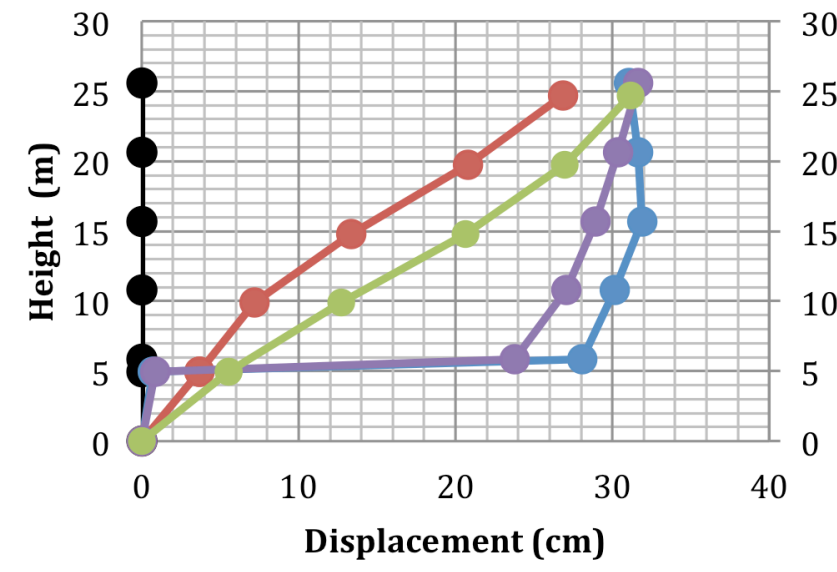

-Structure

-With isolators in direction $\mathrm{x}$

-Without isolators in direction $\mathrm{x}$

-With isolators in direction $\mathrm{Y}$

-Without isolators in direction $Y$

\section{Displacement for MCE earthquake in $X$ and $Y$ direction}

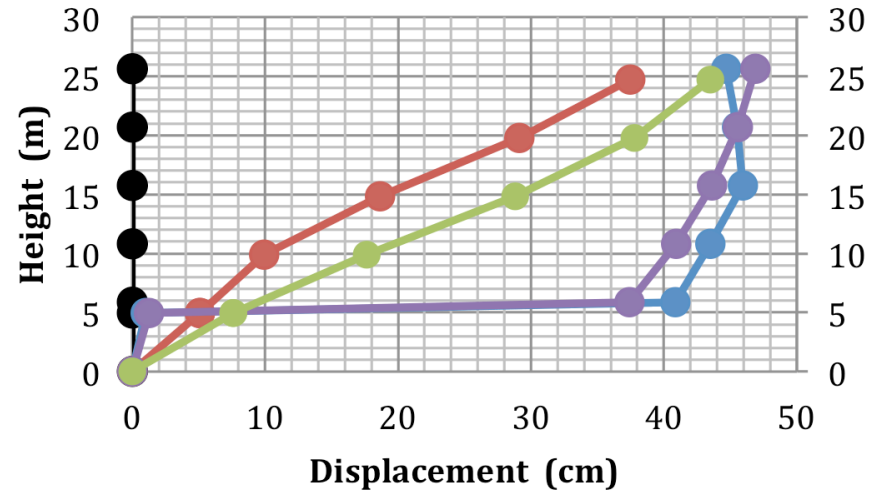

- Structure

-With isolators in direction $\mathrm{x}$

-Without isolators in direction $\mathrm{x}$

-With isolators in direction $Y$

Figure 17. Lateral displacements in the Structural Block with isolators, in the presence of DBE and MCE in two directions. Source: Aguiar et al., 2016.

\section{Remarks and Conclusions}

seismic isolators

This paper has presented a seismic analysis of a 4-floor stairs designed without, which gives access to a structural block with triple friction pendulum seismic isolators. The analysis considered three models with 10 degrees of freedom (M10), 7 degrees of freedom (M7) and 4 degrees of freedom (M4) respectively. It was concluded that the latter is the simplest model, but it does not report reliable results.
The seismic analysis was based on the Spectral Method and the Capacity Spectrum Method, and both methods presented quite similar results. In the professional practice, the Spectral Method is preferred due to its simplicity. Instead, the Capacity Spectrum Method is more elaborated, but it shows how structural members will look after the earthquake, if they suffered any damage or not. 
Finally, the study presents the results obtained from the seismic analysis of the Structural Block with isolators, to which stairs give access to, which considered the isolators' constitutive model of McVitty and Constantinou (2015). A spatial analysis with the Spectral Method was carried out in floor coordinates, in the presence of DBE and MCE. Results show that maximum displacements of approximately $47 \mathrm{~cm}$ are expected, thereby highlighting that it is the isolators that will have the greatest displacement, around $40 \mathrm{~cm}$. Therefore, the relative displacements of the structure in relation to the isolators are around $7 \mathrm{~cm}$, which means that they will not be damaged.

Since the isolated structure has big displacements, it was made sure that the Structural Block of the Stairs, which is made of steel, was a rigid structure; however, this causes displacements of around $15 \mathrm{~cm}$. Consequently, constructive preventive measures were taken in the access of the Stairs Block and the Elevator to the Block with seismic isolators, which have been presented herein.

All these experiences regarding structural and construction analyses are expected to be beneficial for those who are working in the design of buildings with seismic isolators.

\section{Annex A: Anallysis procedure with the spectral method}

1. The degrees of freedom are properly numbered, thereby grouping primary coordinates and secondary coordinates. Then, the stiffness matrix of the structure is obtained by direct assembly (Lamar and Fortoul, 2007).

$$
K=\left[\begin{array}{ll}
K_{a a} & K_{a b} \\
K_{b a} & K_{b b}
\end{array}\right]
$$

Where $\boldsymbol{K}$ is the stiffness matrix of the structure, which is partioned according to the number of primary coordinates in the submatrices $\boldsymbol{K}_{\boldsymbol{a} \boldsymbol{a}}(n a, n a)$; $\boldsymbol{K}_{a b}(n a, n b) ; \boldsymbol{K}_{b a}=\boldsymbol{K}_{a b}^{t} ; \boldsymbol{K}_{b b}(n b, n b)$. Where $n a, n b$, is the number of primary and secondary coordinates.

2. The stiffness matrix associated to the lateral coordinates is determined, and there are three options available: the first is to find the inverse of the matrix (Equation 2), the second is to solve linear equations (Equations 3 and 4) and the third is through the Gauss triangularization method (equation 5). For the latter, primary coordinates are numbered at the end.

$$
\begin{aligned}
& \boldsymbol{K}_{L}=\boldsymbol{K}_{a a}-\boldsymbol{K}_{a b}\left(\boldsymbol{K}_{b b}\right)^{-1} \boldsymbol{K}_{b a} \\
& \boldsymbol{K}_{\boldsymbol{L}}=\boldsymbol{K}_{a a}+\boldsymbol{K}_{a b} \boldsymbol{T} \\
& \boldsymbol{K}_{b b} \boldsymbol{T}=-\boldsymbol{K}_{b a} \\
& {\left[\begin{array}{c}
\mathbf{0} \\
\boldsymbol{Q}_{\boldsymbol{b}}
\end{array}\right]=\left[\begin{array}{ll}
\boldsymbol{I} & -\boldsymbol{T} \\
\mathbf{0} & \boldsymbol{K}_{\boldsymbol{L}}
\end{array}\right]\left[\begin{array}{l}
\boldsymbol{q}_{a} \\
\boldsymbol{q}_{b}
\end{array}\right]}
\end{aligned}
$$

Where $\boldsymbol{q}_{a}, \boldsymbol{q}_{b}$, are the vectors containing the displacements and rotations (generalized coordinates). Equation 4 defines the system of linear equations to be solved. The matrix equation (5) indicates the resulting stiffness matrix following the triangularization to find the lateral stiffness matrix.

3. In the $2 D$ case, the mass matrix $\boldsymbol{M}$ is diagonal and it is composed by the total masses of each floor.

4. The problem of own values and vectors is solved.

$\left(K_{L}-\lambda M\right) \phi=0$

Where $\lambda$ are the own values for finding the vibration frequencies $W_{n}$ and the period $T$, in each vibration mode $\phi$.

$W_{n i}=\sqrt{\lambda_{i}} \quad T_{i}=\frac{2 \pi}{W_{n i}}$

5. The spectral acceleration $A_{d i}$ is found with each period in the inelastic spectrum. A reduction factor $R=4$ was used in the stairs structure.

6. The modal participation factors $\Gamma$ are determined in each mode.

$\Gamma_{i}=\left|\frac{\phi^{(i) t} \boldsymbol{M} \boldsymbol{b}}{\phi^{(i) t} \boldsymbol{M} \phi^{(i)}}\right|$

Where $\boldsymbol{b}$ is the incidence vector of the ground motion in the degrees of freedom. For the $2 D$ case, the vector $\boldsymbol{b}$ is a unit vector.

7. Modal displacements $\boldsymbol{q}^{(i)}$ are found

$\boldsymbol{q}^{(i)}=\left(\frac{T_{i}}{2 \pi}\right)^{2} A_{d i} \Gamma_{i} \boldsymbol{\phi}^{(i)}$

Now, a modal combination criterion should be used to find the resulting displacements. This paper applied the modal combination method of Complete Quadratic Combination (CQC). Chopra (2001).

8. The inelastic displacements $\boldsymbol{q}_{\text {ine }}$ are determined by multiplying the elastic displacements $\boldsymbol{q}$ by the response reduction factor $R$.

9. Finding the inelastic floor drifts $\gamma^{(i)}$.

$\gamma^{(i)}=\frac{q_{\text {ine } i}-q_{\text {ine } i-1}}{h_{i}}$

Where $q_{\text {ine }}, q_{\text {ine } i-1}$, are the inelastic displacements in the floors $i$, and $i-1 ; h_{i}$ is the floor height.

10. The forces in each mode $F^{(i)}$ are determined, and the modal combination criterion CQC is applied for the resultant.

$F^{(i)}=\Gamma_{i} A_{d i} \boldsymbol{M} \boldsymbol{\phi}^{(i)}$

All calculations indicated above have been made in the present paper. Controls based on the seismic standard of minimum base shear, the $P-\Delta$ effect, and calculating the 
accidental torsion, are still pending. Barbat and Bozzo (1997), Chopra (2014).

\section{Annex B: Calculation procedure with the capacity spectrum method}

The Capacity Spectrum Method requires three primary elements: capacity, demand (displacement) and performance (ATC-40, 1996).

\section{Capacity}

The capacity curve of a structure is represented by a pushover curve (nonlinear static analysis). The most convenient way to represent it on a graph is by the base shear and the displacement at the top of the building.

A computer process is needed to achieve severe iterations of static analyses and define the capacity curve (Ger and Cheng, 2012).

Process:

1. Definition of the geometry of the structure, the sections of each element and the degrees of freedom of each knot.

2. Calculation of the actions resulting from gravity loads.

3. Then, they are accumulated to the actions resulting from lateral loads.

The structure is loaded with relatively small lateral forces. A static analysis is made in each iteration, accumulating the resulting actions for the next iteration. Sections will eventually flow, reducing their stiffness EI (Young's Modulus by the moment of Inertia of the section).

It is possible to know the nonlinear behavior of the structure through the variation of the EI stiffness, because this parameter is involved in the static analysis process.

$\boldsymbol{k}_{\mathbf{1}}=\left[\begin{array}{ccc}4 E I / L & 2 E I / L & 0 \\ 2 E I / L & 4 E I / L & 0 \\ 0 & 0 & E A / L\end{array}\right]$

Where $k_{1}$ is the stiffness matrix of a section in reduced local coordinates; $E I$ is the flexural stiffness that changes according to the damage degree of the section; $L$ is the length of the element; $E A$ is the axial stiffness.

Here, actions were calculated by the structural analysis method of stiffness, using stiffness and transformation matrices for reduced, local and generalized systems of each section, and assemblies based on the degree of freedom of each element, in order to obtain the stiffness matrix of the whole structure. Subsequently, the deformations of each degree of freedom and the resulting actions are found.

In order to know the flexural stiffness EI in every stage of a section, it is necessary to know the moment-curvature diagram of every section, since the hypothesis of Bernoulli and Navier shows that:

$$
\boldsymbol{E} \boldsymbol{I}=\frac{M}{\emptyset}
$$

Where $E$ is the Young's Modulus, I is the moment of Inertia of the analyzed section, $M$ is the yield Moment and $\varnothing$ is the Curvature.

4. After several cycles of small lateral loads, accumulating resulting forces, eventually several sections will lose the capacity to resist moments, which is known as a plastic hinge. As mentioned earlier, the structural analysis is based on stiffness and transformation matrices. When a plastic hinge is formed, the problem is that the stiffness matrix of the structure becomes singular and, when calculating the displacements and rotations of each degree of freedom, it is necessary to know the inverse of the stiffness matrix, which is impossible.

$$
\boldsymbol{q}=\boldsymbol{K} \backslash \boldsymbol{Q}
$$

Where $\boldsymbol{K}$ is the Stiffness matrix of the structure, $\boldsymbol{Q}$ is the load Vector in degrees of freedom, $\boldsymbol{q}$ is the displacement or rotations in the degrees of freedom.

This problem can be solved by creating new stiffness matrices for elements and transformation for different systems of plastic hinge formations.

5. Iterations will stop only when the structure collapses. The collapse criterion may include floor drifts greater or equal to 2\% (ASCE 7, 2010; NEC, 2015) or a global drift enough to obtain results at the performance point; generally, at a $4 \%$ limit, the global drift is based on the total height of the building.

Moreover, the software used herein will stop if the stiffness matrix of the structure is singular, because this indicates that the structure is unstable; this situation occurs when several plastic hinges are formed.

\section{Demand}

It is the ground motion during an earthquake. For the nonlinear method, it is easier and more direct to use a set of lateral displacements as a design condition. For a given structure and ground motion, the displacement demand is an estimate of the maximum considered response of a structure during the ground motion. The codes allow obtaining the design spectrum, which relates the response acceleration of the structure with the fundamental period of the structure.

\section{Performance}

In order to verify the performance of the structure, the structure capacity curve and the seismic demand spectrum curve must be placed in the same format: displacement with spectral acceleration (Chopra and Goel 2000, 2001).

The performance must be checked once the capacity and demand curves have been defined (ASCE 41, 2013). A performance check verifies that the structural and nonstructural components are not damaged beyond acceptable limits. 
The performance points represent the maximum considered displacement in the design earthquake, given the fact that the mathematical model directly considers the inelastic effects the material's response. The calculated internal forces are reasonable approximations expected during the design earthquake.

\section{Three-phase constitutive model}

There are different constitutive models dealing with the nonlinear behavior of triple friction pendulum isolators (TFP), among which the following can be highlighted: the equivalent linear method of ASCE 7-10; the 5-phase model proposed by Fenz and Constantinou (2007, 2008), and the three-phase model used in this study, proposed by McVitty and Constantinou (2015). The latter is indicated below in
Figure A1, which shows the geometry and nomenclature of the TFP isolator, considering the dimensions used in the constructions of the Universidad de las Fuerzas Armadas ESPE, in Ecuador.

The following equations are necessary to describe the three-phase model:

$R_{i, e f f}=R_{i}-h_{i} \quad$ Para i de 1 a 4.

$d_{i}^{*}=\frac{R_{i, e f f}}{R_{i}}$

Where $R$ is the radius of curvature; $h$ is the height, indicated in Figure $A 1 ; R$ is the effective radius of curvature; $d_{i}^{*}$ is the displacement capacity. The subscript $i$ varies from 1 to 4 . The 3 phases or regimes of the model are the following:

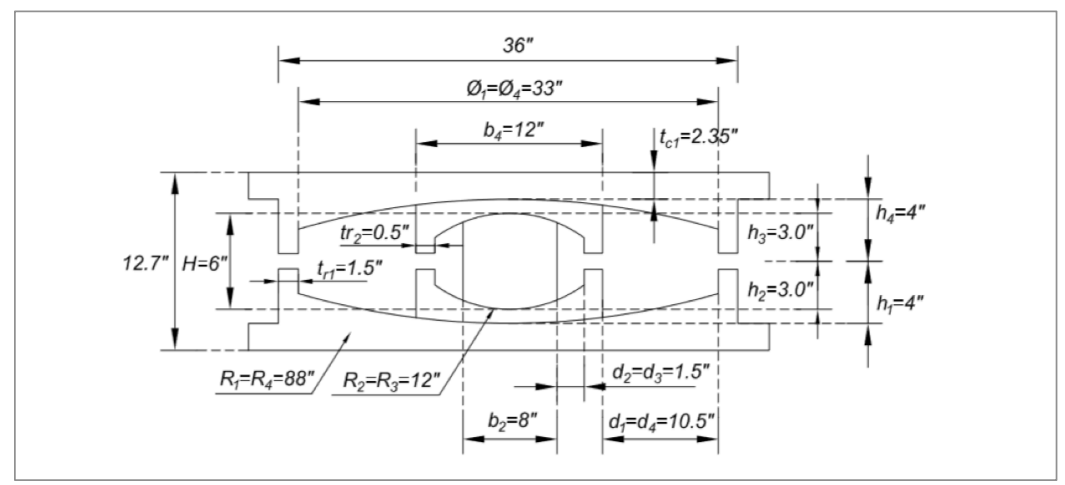

Figure A1. Geometry of the triple friction pendulum isolator FTP8833 / 12-12 / 8-6, used in the construction of the Universidad de las Fuerzas Armadas - ESPE.

\section{Regime 1}

Here, the displacement occurs only in plates 2 and 3.

$0 \leq u \leq u^{*}$

$u^{*}=2\left(\mu_{1}-\mu_{2}\right) R_{2, e f f}$

$F=\frac{W}{2 R_{2, e f f}} u+\mu_{2} W$
Where $u$ is the lateral displacement of the isolator; $F$ is the applied lateral force; $W$ is the weight on the isolator. The left side of Figure A2 shows the inner isolator sliding along surfaces 2 and 3; the right side shows the corresponding hysteresis diagram.

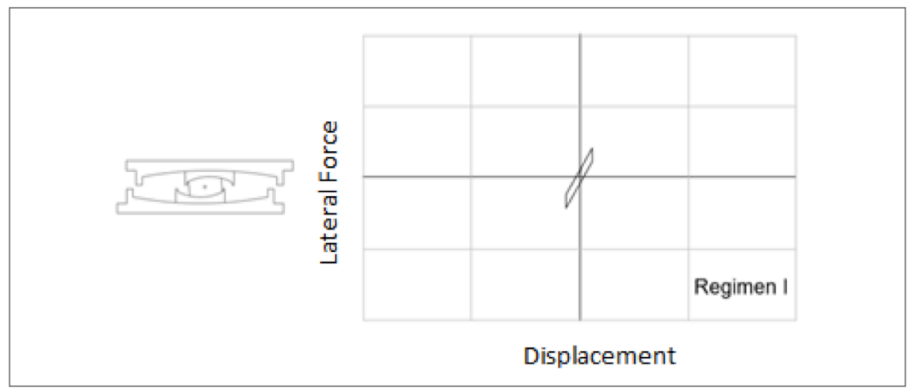

Figure A2. Isolator Performance in Phase I. Source: McVitty and Constantinou (2015) 
Regime 2

The movement in the inner isolator reaches the stops and starts sliding along surfaces 1 and 4. Normally, in the event of an earthquake of medium to high intensity, the isolator works in this regime. The following equations and Figure A3 show the corresponding hysteresis curve.

$$
\begin{aligned}
& u^{*} \leq u \leq u^{* *} \\
& u^{* *}=u^{*}+2 d_{1}^{*} \\
& F=\frac{W}{2 R_{1, e f f}}\left(u-u^{*}\right)+\mu_{1} W
\end{aligned}
$$

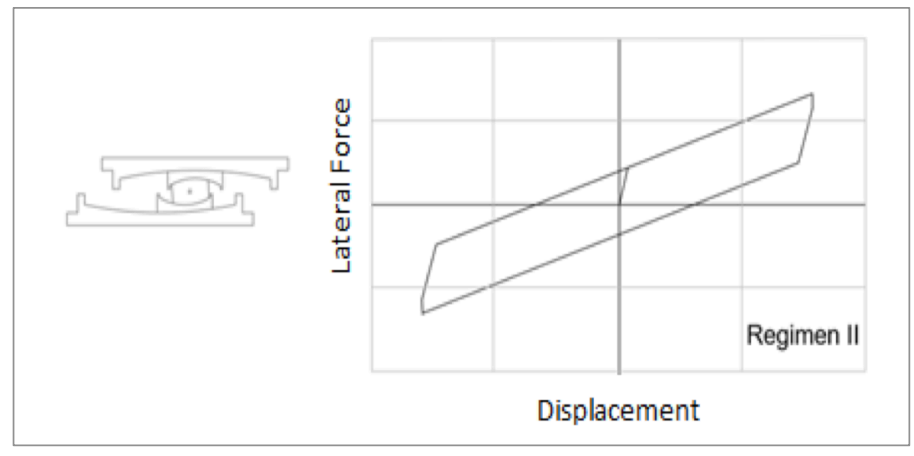

Figure A3. Isolator Performance in Regime II. Source: McVitty and Constantinou (2015)

\section{Regime 3}

This regime occurs when the earthquake is extremely strong and the inner isolator hits the outer stops; in these conditions, the inner isolator begins to slide along surfaces 2 and 3. Figure A4 shows the calculation equations and the performance.

$$
\begin{aligned}
& u^{* *} \leq u \leq u_{\text {cap }} \\
& u_{\text {cap }}=2 d_{1}^{*}+2 d_{2}^{*} \\
& F=\frac{W}{2 R_{2,1 f f}}\left(u-u^{* *}\right)+\frac{W}{2 R_{1 e f f}}\left(u^{* *}-u^{*}\right)+\mu_{1} W
\end{aligned}
$$

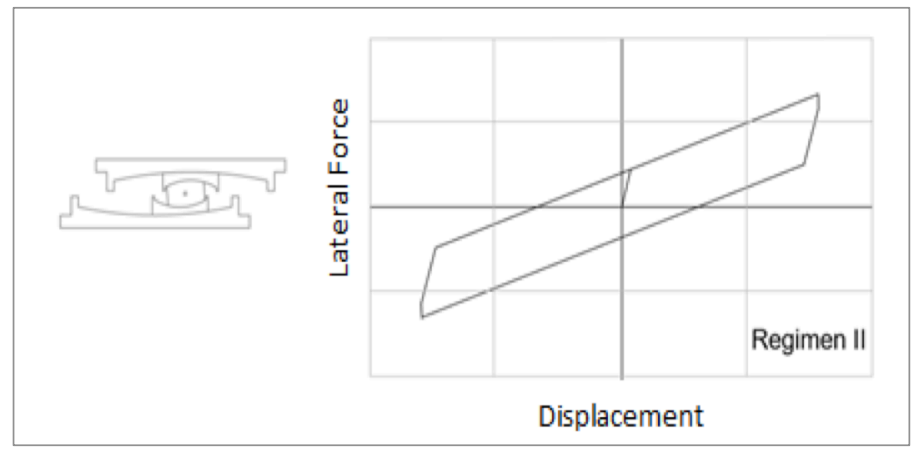

Figura A4. Isolator Performance in Regime III. Source: McVitty and Constantinou (2015)

\section{References}

Aguiar R., Pazmiño E. (2016), Detalles constructivos debido a los aisladores sísmicos en las construcciones de la Universidad de Fuerzas Armadas ESPE en Ecuador, Revista Internacional de Ingeniería de Estructuras, 21 (2), 217-256. Disponible en: http://www.riie.espe.edu.ec.

Aguiar R., Andrade V., Guaygua B., Piedra P. (2016), Aplicación del Método Espectral en los Bloques 6 y 7 con aisladores sísmicos de la UFAESPE en Ecuador, Revista Ciencia, 18 (1), 67-92. Disponible en: http://www.revista_ciencia.espe.edu.ec

ASCE Standard (ASCE/SEI 41), Seismic Evaluation and Retrofit of Existing Buildings, American Society of Engineers, 2013.

ASCE Standard (ASCE/SEI 7-10), Minimum Design Loads for Buildings and Other Structures, American Society of Civil Engineers, Reston, Virginia.

ATC-40 (1996), Seismic evaluation and retrofit of concrete buildings, Redwood City, California: Applied.

Bonifaz H. (2015), Informe de suelos. Edificio de Investigaciones. Laboratorio de Ensayo de Materiales LEM-ESPE, 33 p., Sangolquí.

Constantinou M., Aguiar R., Morales E., Caiza P. (2016), “Desempeño de aislador FPT8833/12-12/8-5 en el análisis sísmico del Centro de Investigaciones y de Post Grado", Revista Internacional de Ingeniería de Estructuras, 21 (1), 1-25. Disponible en: http://www.riie.espe.edu.ec 
Chopra A. K. (2001), Dynamic of structures: Theory and aplications to earthquake engineering, $2^{\text {nd }}$ edn. Prentice Hall: Saddle River New York.

Chopra A. K. (2014), Dynamic of Structures Theory and application to earthquake engineering. $4^{\text {th }}$ edition.

Fadi F. and Constantinou M. (2010), Evaluation of simplified methods of analysis for structures with triple friction pendulum isolators, Earthquake Engineering and Structural Dynamics, 39, 5-22.

Fenz D., Constantinou M., (2007), Mechanical behavior of multi-spherical sliding bearings, Technical Report MCEER-08-0007, Multidisciplinary Center for Earthquake Engineering Research. Multidisciplinary Center for Earthquake Engineering Research. Available at http://mceer.buffalo.edu/publications/catalog/reports/Mechanical-Behavior-of-Multi-Spherical-Sliding-Bearings-MCEER-08-0007.html

Fenz D.M. and Constantinou M.C. (2008), Development, implementation and verification of Dynamic Analysis Models for Multi-Spherical sliding bearings. Report No. MCEER-08-0018, Multidisciplinary Center for Earthquake Engineering Research, Buffalo, NY. Available at http://mceer.buffalo.edu/publications/catalog/reports/Development-Implementation-and-Verification-of-Dynamic-Analysis-Models-for-MultiSpherical-Sliding-Bearings-MCEER-08-0018.html

Ger J. and Cheng F. Y. (2012), Seismic Design Aids for Nonlinear Pushover Analysis of Reinforced Concrete and Steel Bridges. Boca Raton: Taylor \& Francis Group.

Lamar S. and Fortoul C. (2007), Análisis estático de estructuras. Formulación matricial. Editorial CITECI, Caracas, Venezuela.

McVitty W.J. y Constantinou M.C. (2015), Property Modification Factors for Seismic Isolators: Design Guidance for Buildings, MCEER Report. 15-0005, 242 p. Multidisciplinary Center for Earthquake Engineering Research, State University of New York at Buffalo, Buffalo, NY, 2015. Available at http://mceer.buffalo.edu/publications/catalog/reports/Property-Modification-Factors-for-Seismic-Isolators-Design-Guidance-forBuildings-MCEER-15-0005.html

NEC-15 (2015), Norma Ecuatoriana de la Construcción NEC-SE-DS, Ministerio de la Vivienda MIDUVI. 